\title{
Comprehensive Analysis of Internal and External Factors Affecting the Development of the Third Industry in China
}

\author{
Zelong Fang \\ Institute of Finance, Jinan University, Guangzhou, China \\ Email: fangz107@foxmail.com
}

How to cite this paper: Fang, Z. L. (2020). Comprehensive Analysis of Internal and External Factors Affecting the Development of the Third Industry in China. Modern Economy, 11, 977-993.

https://doi.org/10.4236/me.2020.114072

Received: February 28, 2020

Accepted: April 24, 2020

Published: April 27, 2020

Copyright $\odot 2020$ by author(s) and Scientific Research Publishing Inc. This work is licensed under the Creative Commons Attribution International License (CC BY 4.0).

http://creativecommons.org/licenses/by/4.0/

\begin{abstract}
This article mainly studies the relevant factors that affect the development of China's tertiary industry, including external and internal aspects. For the internal factors, we choose the financial industry, tourism and education. And for the external factors, we selected factors such as the level of national economic development, urbanization, science and education, living standards of residents, degree of openness to the outside world, and labor in the tertiary industry. Based on the internal and external factors selected above, we explore the internal dynamics of the development of the tertiary industry in China and the external factors that influence the development of the tertiary industry. This paper selects data from the national level and the provincial level for the internal and external aspects. For internal factors, we selected national statistics from 1994 to 2015 at the national level. For external factors, we selected data from the National Bureau of Statistics from 1991 to 2009, and provincial data from the National Bureau of Statistics from 2004 to 2013. We have processed all data to eliminate the influence of price factors and dimensional factors, and applied multiple linear regression analysis methods to the data to establish a multiple linear regression equation. From the perspective of empirical analysis, we have obtained the specific effects of the above factors on the development of China's tertiary industry, and confirmed that the above five external factors are important factors in the development of China's tertiary industry, as well as the outstanding contribution of the financial and education industries to China's tertiary industry. In the end, based on the analysis results, we obtained the degree of influence of various factors on the tertiary industry and made recommendations for the development of the tertiary industry in China in the future.
\end{abstract}

\section{Keywords}

Third Industry Development, Regression Analysis, Manufacturing Industries, 


\section{Introduction}

\subsection{Definition}

The division of the three major industries is a common classification of industrial structure in the world, but the division between different countries is not consistent. According to the statistical yearbook of the National Bureau of statistics, the three major industries in China are: the primary industry refers to agriculture, forestry, animal husbandry and fishery; the secondary industry refers to mining industry, manufacturing industry, power, gas and water production and supply industry, and construction industry; the tertiary industry is an industry other than the above mentioned industries.

The tertiary industry also includes four parts: the first part is the circulation department, including transportation, post and telecommunications, commercial catering, material supply and marketing, and warehousing; the second part is the department that serves production and living, including finance, insurance, geological survey, real estate, public utilities, residential services, tourism, consulting and information services, and various technical services; the third part is the department that serves to improve the scientific and cultural level and the quality of the residents, including education, culture, radio and television, scientific research, health, sports and social welfare.

\subsection{Background}

Since the reform and opening up in 1978, China's economy has grown rapidly. However, its growth mainly depends on an extensive economy driven by resources, capital and cheap labor. Beginning in the 1990s, the country established special economic zones, began to carry out industrial structure upgrading and transformation, and vigorously developed the tertiary industry represented by high-tech and service industries. As a result, the tertiary industry has developed by leaps and bounds. As shown in Figure 1, the proportion of the added value of the tertiary industry in the national economy is gradually increasing, indicating that the tertiary industry is playing an increasingly important role in the national economy.

Now the tertiary industry is playing an increasingly important role in China's national economy. We can draw two conclusions based on the "Petty-Clark Law” formally put forward by Colin Clark (1940) based on William Petty's research. The first conclusion is that with the continuous development of the economy, the level of per capita national income will continue to increase, and the employment population will first be transferred from the primary industry to the secondary industry, and the secondary industry will dominate the national economy. The second conclusion is that with the further development of the 


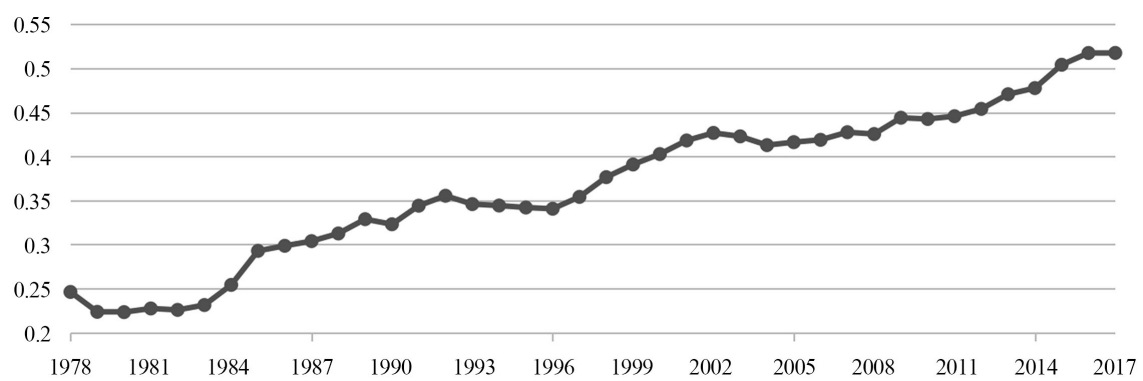

Figure 1. Line chart of the proportion of value added of the tertiary industry.

economy, the level of per capita national income will further increase, and the employment population will be transferred to the tertiary industry in large numbers, promoting the development of the tertiary industry, and eventually the tertiary industry will dominate the national economy. According to the "Industrial Structure Conversion Theory" put forward by Kuznets in his book "National Income and Its Composition" in 1941, it can be seen that with the development of the economy, the proportion of investment in the tertiary industry has increased rapidly in the post-industrial era. It is larger than the secondary industry and larger than the primary industry. This shows that the development of the tertiary industry is of great significance to the national economic development.

Therefore, we need to explore the main factors of the development of the tertiary industry from both internal and external perspectives, find out the internal relationship between the various influencing factors, and better promote the development of the tertiary industry. What are the main factors in the development of the tertiary industry in China? This paper will use Stata software to process the data and regression analysis, draw conclusions, and explore its influencing factors.

\subsection{Significance}

Although world economists from different countries have different perspectives and methods in their research on the tertiary industry, they have reached a consensus conclusion: the development level of the tertiary industry represents the main driving force for the future economic development of a country and region. Therefore, it is of great significance to study the influencing factors of the development of the tertiary industry in China for the further development of China's overall economy.

1) It is conducive to the sustainable development of China's economy and is in line with China's long-term economic development strategy.

2) It is beneficial to optimize China's industrial structure and promote sustainable economic development.

3) It is conducive to promoting employment and achieving long-term economic and social stability.

4) It is conducive to further advancing China's urbanization process.

5) It can give some development suggestions and theoretical basis to specific 
government departments.

\section{Literature Review}

\subsection{Foreign Literature}

At present, there are quite a lot of related literatures on the research of the tertiary industry at home and abroad. Among them, foreign scholars have analyzed the development factors of the tertiary industry earlier, and there was a large amount of research literature before the 1970s. With the development of the western economy, the proportion of the tertiary industry in many developed countries was generally above $60 \%$. Since then, research on the factors affecting the tertiary industry has gradually decreased. Compared with foreign countries, China's tertiary industry is still in the development stage, and research on the factors affecting the tertiary industry is more realistic.

Among the foreign research results, there are many empirical studies on the tertiary industry. Colin Clark (1940), a famous British economist. In the book "Conditions for Economic Progress", he said that he had collected statistical data of many countries for in-depth study, which mainly covered the statistical data of economic development of western developed countries, and finally got "Petty-Clark Law". In the early stage of the country's economic development, in order to survive, a large number of laborers participated in the production of the primary industry. The output value of the primary industry accounted for the majority of national income. With the development of the economy, the country's labor force began to move from the primary industry to the secondary industry. The proportion of the output value of the secondary industry in national income increased, and the proportion of the primary industry declined. As the level of economic development further improved, the labor force began to move to the tertiary industry, and the proportion of the tertiary industry in national income increased. Eventually, the proportion of the tertiary industry exceeded the primary and secondary industries, which became the main driving force for the country's economic development.

In the book "Economic Growth of Countries" published by American economist Simon Kuznets (1999), he conducted an empirical analysis of statistical data in many countries and reached the following conclusions. In the early stage of economic development, the proportion of the primary industry in the total national income was higher than that of the secondary industry. With the impact of the Industrial Revolution on the economy, the proportion of the primary industry in total national income began to decline. And the proportion of the secondary industry in the total national income began to rise and eventually exceeded the proportion of the primary industry. When the economic level further improved, the proportion of the secondary industry in the total national income began to decline. And the proportion of the tertiary industry's participation in the total national income began to rise, eventually surpassing the proportion of the primary and secondary industries, and dominated the national income. 


\subsection{Domestic Literature}

There are many domestic studies on the specific internal and external factors affecting the development of the tertiary industry. The literatures based on the internal industry classification of the tertiary industry are as follows:

Su et al. (2011) targeted China's tourism industry and the tertiary industry, selected relevant statistical data from 1982 to 2008, analyzed the relationship between tourism and tertiary industry growth, and reached the following conclusions: the development potential of China's tourism industry is huge, and the development of tourism industry is constantly accelerating, and its position in the growth process of the national economy is constantly rising. Tourism will have a comprehensive promotion effect on China's traditional service industry, and it will significantly promote new-type service industries, especially service industries such as information, finance and tourism real estate.

Luo et al. (2012) pointed out in the study that in the long run, there is a long-term balanced co-integration relationship between China's tourism development, economic growth, and tertiary industry growth. At the same time, the tourism industry is of great importance in China's economic development, and it has a strategic and pillar industry status in economic development.

Chen et al. (2010) found in the study that financial scale can promote the proportion of the output value of the tertiary industry, but financial efficiency has a restraining effect. Financial structure, financial openness, and financial rule of law have no significant impact on the industrial structure. The influence of the financial system on various industries within the tertiary industry is quite different. Finance promotes the tertiary industry.

Zeng and Wang (2007) used China's time series data from 1952 to 2005 to conduct an empirical test on the theoretical assumptions of financial development and industrial structure change. It was found that financial development has played a positive and important role in promoting the development of the tertiary industry.

Zhang and Zhang (2014) studied the impact on the development of the tertiary industry since the implementation of China's higher education expansion policy in the late 1990s. It is concluded that the development of education promotes the promotion of the tertiary industry.

The domestic research literature on the external factors affecting the development of the tertiary industry is as follows:

Xue (2010) collected data from Henan Province from 1978 to 2007, and used regression analysis to analyze the correlation between the tertiary industry and economic growth in Henan Province. Finally, in order to promote the development of the tertiary industry in Henan Province, proposals were made to accelerate the process of urbanization and improve the internal structure of the tertiary industry.

$\mathrm{Li}$ and Jiang (2010) collected the statistical data of 31 provinces and autonomous regions in China in 2008, and used the principal component analysis 
method to analyze the development level of the tertiary industry in 31 provinces and autonomous regions and municipalities in China. It is concluded that there is an interaction and mutual promotion relationship between the development level of the tertiary industry and the economic aggregate of each province.

Jiang (2010) conducted an empirical analysis of the factors affecting the development of the tertiary industry in Jiangsu Province. The results show that the direction of change in the tertiary industry is consistent with the direction of changes in residents' income levels and urbanization rates.

Wang used EVIEWS statistical software to analyze and found that there is no obvious relationship between the growth of China's tertiary industry and the level of per capita income, but there is a positive correlation between it and the rate of economic growth.

Tan (2011) selected Anhui Province's economic data from 1995 to 2009 for empirical analysis, and clarified the different impacts of various factors on the development of the tertiary industry.

Zhao (2012) established a multiple regression model based on 1995-2009 economic data of Hebei Province. It is concluded that factors such as per capita income level, urbanization rate, and degree of foreign trade are positively related to the development process of the tertiary industry in Hebei Province.

\section{Model Establishment and Analysis of Empirical Results}

\subsection{Factors Analysis}

For the factors that affect the development of the tertiary industry, this paper first makes a theoretical analysis, and then uses the selected factors as variables to construct a regression model. First of all, we start with the analysis of the internal factors of the tertiary industry. According to the previous literature, we can find that the three main industries of the tertiary industry are: finance, tourism and education. Therefore, we consider them as internal factors affecting the tertiary industry. As for the external factors affecting the development of the tertiary industry, we consider factors such as the level of economic development, the level of urbanization, the standard of living of residents, the level of science and education, the labor force of the tertiary industry, and the degree of opening up to the outside world.

\subsection{Model Establishment}

\subsubsection{Internal Factor Model}

The tertiary industry value-added growth rate is selected as the explained variable, expressed as $y_{1}$, and the financial industry output value, tourism output value, and education input are used as explanatory variables, which are expressed as $x_{1}, x_{2}$ and $x_{3}$. Therefore, the equation for the Internal Factor Model is as follows:

$$
y_{1}=\alpha_{0}+\alpha_{1} x_{1}+\alpha_{2} x_{2}+\alpha_{3} x_{3}+u_{1} .
$$

$u_{1}$ in Equation (1) represents a random error term. 


\subsubsection{External Factor Model}

This paper selects the tertiary industry's added value growth rate as the explained variable, which is represented by $y_{2}$. Take the growth rate of per capita GDP, the growth rate of the proportion of urban population, the growth rate of disposable income of urban residents, the growth rate of total imports and exports of goods, the growth rate of the proportion of employed persons in the tertiary industry, and the growth rate of the number of graduates of ordinary colleges and universities as explanatory variables. And expressed as $z_{1}, z_{2}, z_{3}$, $z_{4}, z_{5}$ and $z_{6}$. Therefore, the equation for the External Factor Model is as follows:

$$
y_{2}=\beta_{0}+\beta_{1} z_{1}+\beta_{2} z_{2}+\beta_{3} z_{3}+\beta_{4} z_{4}+\beta_{5} z_{5}+\beta_{6} z_{6}+u_{2} .
$$

$u_{2}$ in Equation (2) represents a random error term.

\subsection{Data Processing}

This paper directly selects the tertiary industry's GDP to represent the development index of the tertiary industry. The financial industry and the tourism industry use their respective annual output values. For the education industry, we choose the country's annual input value. Since some data are no longer counted by the National Bureau of statistics after 2017, we can no longer get the latest data. This paper selects national level data from 1994 to 2017 from the National Bureau of Statistics. The selected data have the same dimensions and have the same price index each year, so there is no need to eliminate the impact of price factors on value indicators. Therefore, the available summary data is shown in Table 1 below.

As for the index for measuring the development level of the tertiary industry, the annual added value of the tertiary industry is selected here as its measurement index. For the other six factors, the per capita GDP represents the level of economic development, the proportion of urban population represents the level of urbanization, the disposable income of urban residents represents the living standard of residents, and the total value of imports and exports of goods represents the degree of openness to the outside world, the proportion of employees in the tertiary industry represents the labor force level of the tertiary industry, and the number of graduates from ordinary colleges and universities represents the level of science and education. In order to avoid co-linearity and endogenous problems that may exist between variables, this paper uses data from the explanatory variables of the previous year to examine the impact on the explained variables of the current year.

For the selected indicators, data are selected from the national and provincial levels to explore the influencing factors of the development of the tertiary industry in China. At the national level, data from 1994 to 2017 were selected from the National Bureau of Statistics. At the provincial level, data from 31 provinces of China from 2004 to 2013 were selected from the National Bureau of Statistics. In addition, the influence of price factors on value index data and the dimensions 
of all factor data need to be removed.

Data preprocessing: The data in this article uses the consumer price index of different years to obtain the actual value after excluding the influence of price factors, thereby eliminating the impact of price factors on value indicators. The data at the national level are calculated using the 1990 data as the base period data to calculate the growth rates of the indicators, and the provincial level data are calculated using the 2003 data as the base period data to calculate the growth rates of the indicators. We perform regression analysis on its growth rate as a variable to eliminate the impact of the dimension.

The data obtained after processing are shown in Table 2 and Table 3.

Table 1. Statistics of influencing factors at the national level (Unit: 100 million yuan).

\begin{tabular}{|c|c|c|c|c|}
\hline Year & $\begin{array}{c}\text { Tertiary } \\
\text { industry's GDP }\end{array}$ & $\begin{array}{c}\text { Financial industry } \\
\text { output }\end{array}$ & $\begin{array}{c}\text { Tourism } \\
\text { output value }\end{array}$ & $\begin{array}{l}\text { Education } \\
\text { investmen }\end{array}$ \\
\hline 1994 & $16,712.5$ & 2556.5 & 1023.5 & 894.7 \\
\hline 1995 & $20,641.9$ & 3209.7 & 1375.7 & 1026.9 \\
\hline 1996 & $24,107.2$ & 3698.3 & 1638.4 & 1192.9 \\
\hline 1997 & $27,903.8$ & 4176.1 & 2112.7 & 1332.5 \\
\hline 1998 & $31,558.3$ & 4314.3 & 2391.2 & 1508.0 \\
\hline 1999 & $34,934.5$ & 4484.9 & 2831.9 & 1685.6 \\
\hline 2000 & $39,897.9$ & 4836.2 & 3175.5 & 1915.8 \\
\hline 2001 & $45,700.0$ & 5195.3 & 3522.4 & 2352.7 \\
\hline 2002 & $51,421.7$ & 5546.6 & 3878.4 & 2785.3 \\
\hline 2003 & $57,754.4$ & 6034.7 & 3442.3 & 3153.8 \\
\hline 2004 & $66,648.9$ & 6586.8 & 4710.7 & 3365.9 \\
\hline 2005 & $77,427.8$ & 7469.5 & 5285.9 & 3974.8 \\
\hline 2006 & $91,759.7$ & 9951.7 & 6229.7 & 4780.4 \\
\hline 2007 & $115,810.7$ & $15,173.7$ & 7770.6 & 7122.3 \\
\hline 2008 & $136,805.8$ & $18,313.4$ & 8749.3 & 9010.2 \\
\hline 2009 & $154,747.9$ & $21,798.1$ & $10,183.7$ & $10,437.5$ \\
\hline 2010 & $182,038.0$ & $25,680.4$ & $12,579.8$ & $12,550.0$ \\
\hline 2011 & $216,098.6$ & $30,678.9$ & $19,305.4$ & $16,497.3$ \\
\hline 2012 & $244,821.9$ & $35,188.4$ & $22,706.2$ & $21,242.1$ \\
\hline 2013 & $277,959.3$ & $41,191.0$ & $26,276.1$ & $22,001.7$ \\
\hline 2014 & $308,058.6$ & $46,665.2$ & $30,311.9$ & $23,041.7$ \\
\hline 2015 & $346,149.7$ & $57,872.6$ & $34,195.1$ & $26,271.8$ \\
\hline 2016 & $383,365.0$ & $61,121.7$ & $39,390.0$ & $28,072.8$ \\
\hline 2017 & $427,031.5$ & $65,748.9$ & $45,660.8$ & $30,153.2$ \\
\hline
\end{tabular}

Note: Data from National Bureau of Statistics. 
Table 2. Statistics of influencing factors at the national level.

\begin{tabular}{llllll}
\hline & Number & Mean & $\begin{array}{l}\text { Standard } \\
\text { deviation }\end{array}$ & Minimum & Maximum \\
\hline Tertiary industry added value growth rate & 24 & 4.23 & 2.93 & 1.20 & 12.69 \\
GDP growth rate per capita & 24 & 2.98 & 1.73 & 1.11 & 6.49 \\
Growth rate of urban population & 24 & 0.38 & 0.29 & 0.02 & 0.79 \\
$\begin{array}{l}\text { Household disposable income growth rate } \\
\text { Growth rate of total imports and exports }\end{array}$ & 24 & 2.61 & 1.21 & 1.09 & 4.74 \\
$\begin{array}{l}\text { of goods } \\
\text { Growth rate of the proportion of employees }\end{array}$ & 24 & 0.49 & 0.25 & 0.02 & 0.92 \\
$\begin{array}{l}\text { in the tertiary industry } \\
\text { Growth rate of college graduates }\end{array}$ & 24 & 2.13 & 2.71 & -0.07 & 7.65 \\
\hline
\end{tabular}

Note: Data from National Bureau of Statistics.

Table 3. Statistics of province level influencing factors.

\begin{tabular}{|c|c|c|c|c|c|}
\hline & Number & Mean & $\begin{array}{l}\text { Standard } \\
\text { deviation }\end{array}$ & Minimum & Maximum \\
\hline Tertiary industry added value growth rate & 310 & 5.23 & 4.93 & 0.87 & 14.67 \\
\hline $\begin{array}{l}\text { Growth rate of total imports and exports of } \\
\text { goods (R1) }\end{array}$ & 310 & 12.52 & 30.14 & -47.50 & 152.08 \\
\hline Growth rate of urban population (R2) & 310 & 0.36 & 0.46 & 0.00 & 1.32 \\
\hline Growth rate of college graduates (R3) & 310 & 3.02 & 4.92 & -0.28 & 8.97 \\
\hline $\begin{array}{l}\text { Household disposable income growth rate } \\
\text { (R4) }\end{array}$ & 310 & 3.54 & 2.54 & 0.87 & 9.46 \\
\hline $\begin{array}{l}\text { Growth rate of the proportion of employees } \\
\text { in the tertiary industry (R5) }\end{array}$ & 310 & 0.76 & 1.10 & 0.01 & 1.82 \\
\hline GDP growth rate per capita (R6) & 310 & 3.12 & 3.01 & 0.77 & 11.39 \\
\hline
\end{tabular}

Note: Data from National Bureau of Statistics.

\section{Empirical Analysis for Internal Factor Model}

\subsection{Analysis of Single Influencing Factors}

Aiming at the three factors in the Internal Factor Model, analyze the influence of a single factor on the development of the tertiary industry. Let the coefficients of other factors be 0 , and the results obtained by regression using STATA are shown in Table 4.

It can be seen from Table 4 that the $\mathrm{P}$ value corresponding to the $\mathrm{T}$ statistic of each regression coefficient is less than 0.01 , indicating that they all passed the significance test of non-zero coefficients. And the goodness of fit is about 0.8 , which indicates that each factor has a good degree of interpretation of the tertiary industry, indicating that each industry change is positively related to the development of the tertiary industry, and has a promoting effect on the development of the tertiary industry. 
Table 4. Statistics of province level influencing factors.

\begin{tabular}{cccc}
\hline & $\begin{array}{c}\text { Financial } \\
\text { industry output }\end{array}$ & $\begin{array}{c}\text { Tourism } \\
\text { output value }\end{array}$ & $\begin{array}{c}\text { Education } \\
\text { investment }\end{array}$ \\
\hline $\begin{array}{c}\text { Tertiary industry } \\
\text { added value growth rate }\end{array}$ & $0.002^{* * *}$ & $0.004^{* * *}$ & $0.005^{* * *}$ \\
Intercept & $(0.000)$ & $(0.000)$ & $(0.000)$ \\
$\mathrm{N}$ & $0.376^{* * *}$ & $0.379^{* * *}$ & $0.376^{* * *}$ \\
$\mathrm{R}^{2}$ & $(0.009)$ & $(0.008)$ & $(0.126)$ \\
& 24 & 24 & 24 \\
\hline
\end{tabular}

Note: ${ }^{*}$ indicates $p<0.10$, significant at $10 \%$; ${ }^{* *}$ indicates $p<0.05$, significant at $5 \%$; ${ }^{* * *}$ indicates $p<0.01$, significant at $1 \%$. Data from China Statistical Yearbook.

\subsection{Analysis of Multiple Influencing Factors}

Because there may be internal connections between the factors, and the data may have multiple colinearity, the three internal factors are combined to observe the impact on the development of the tertiary industry again. The results of regression analysis of the data using Stata software are shown in Table 5.

According to the regression results in Table 5, it can be found that the multifactor regression effect is different from the single factor regression. From the data of column (1) and column (4), we can see that the coefficients of tourism variables are -0.012 and -0.013 and they are both significant and negative. In column (4), it can be seen that the other two variables are positive promoters. We can see from this that the development of the tourism industry has become negatively related to the development of the tertiary industry, and the financial industry and education have maintained a positive correlation with the tertiary industry. This may be due to the greater impetus given by the financial and education industries to the development of the tertiary industry, and the promotion effect of the tourism industry is less than the average, so the tourism industry shows a negative correlation. We will elaborate on this later in the conclusion section.

\section{Empirical Analysis for External Factor Model}

\subsection{National Level Data Analysis}

\subsubsection{Analysis of Single Influencing Factors}

For the six factors in the External Factor Model, we analyze the influence of a single factor on the development of the tertiary industry. Let the coefficients of other factors be 0 , and use Stata software to perform regression on the data. The results are shown in Table 6.

It can be seen from Table 6 that after excluding the impact of endogenous problems, regression of the growth rate of the added value of the tertiary industry for each factor alone can be found that the $\mathrm{P}$ value corresponding to the $\mathrm{T}$ statistic of each coefficient is less than 0.01 , which means that all factors have 
passed the significance test with non-zero coefficients. And the goodness of fit is above 0.8 , indicating that each factor has a good degree of explanation for the tertiary industry. Each factor is positively related to the development of the tertiary industry and has a promoting effect on the development of the tertiary industry. This is corroborated by the findings of Jiang (2010) and Zhao (2012).

\subsubsection{Analysis of Multiple Influencing Factors}

Because there may be internal connections between the factors, and the data may have multiple colinearity, all the external factors are combined to observe the impact on the development of the tertiary industry again. The results of regression analysis of the data using Stata software are shown in Table 7.

Table 5. Multivariate regression analysis results 1.

\begin{tabular}{ccccc}
\hline & \multicolumn{5}{c}{ Tertiary industry added value growth rate } \\
\cline { 2 - 5 } & $(1)$ & $(2)$ & $(3)$ & $(4)$ \\
\hline Financial industry output & & $0.005^{* *}$ & -0.003 & $0.006^{*}$ \\
Tourism output value & $-0.012^{* *}$ & -0.007 & & $(0.005)$ \\
& $(0.007)$ & $(0.006)$ & & $-0.013^{* *}$ \\
Education investment & $0.025^{* * *}$ & & $0.003)$ & $(0.004)$ \\
Intercept & $(0.008)$ & & $(0.006)$ & $0.017^{* *}$ \\
& $5.818^{* * *}$ & $5.793^{* * *}$ & $5.836^{* * *}$ & $5.809^{* * *}$ \\
$\mathrm{~N}$ & $(0.122)$ & $(0.149)$ & $(0.132)$ & $(0.127)$ \\
$\mathrm{R}^{2}$ & 24 & 24 & 24 & 24 \\
& 0.863 & 0.802 & 0.842 & 0.871 \\
\hline
\end{tabular}

Note: ${ }^{*}$ indicates $p<0.10$, significant at $10 \%$; ${ }^{* *}$ indicates $p<0.05$, significant at $5 \%$; ${ }^{* *}$ indicates $p<0.01$, significant at $1 \%$. Data from China Statistical Yearbook.

Table 6. Univariate regression analysis results 2.

\begin{tabular}{ccccccc}
\hline & $\mathrm{R} 1$ & $\mathrm{R} 2$ & $\mathrm{R} 3$ & $\mathrm{R} 4$ & $\mathrm{R} 5$ & $\mathrm{R} 6$ \\
\hline $\begin{array}{c}\text { Tertiary industry } \\
\text { added value growth rate }\end{array}$ & $0.656^{* * *}$ & $10.697^{* * *}$ & $1.153^{* * *}$ & $2.834^{* * *}$ & $10.844^{* * *}$ & $1.943^{* * *}$ \\
Intercept & $(0.029)$ & $(1.043)$ & $(0.044)$ & $(0.078)$ & $(1.715)$ & $(0.036)$ \\
& $0.960^{* * *}$ & $0.572^{*}$ & $2.310^{* * *}$ & $-2.174^{* * *}$ & -0.652 & $-1.000^{* * *}$ \\
$\mathrm{~N}$ & $(0.180)$ & $(0.283)$ & $(0.204)$ & $(0.187)$ & $(0.834)$ & $(0.106)$ \\
$\mathrm{R}^{2}$ & 24 & 24 & 24 & 24 & 24 & 24 \\
& 0.971 & 0.903 & 0.953 & 0.991 & 0.802 & 0.996 \\
\hline
\end{tabular}

Note: ${ }^{*}$ indicates $p<0.10$, significant at $10 \%$; ${ }^{* *}$ indicates $p<0.05$, significant at $5 \%$; $* *$ indicates $p<0.01$, significant at $1 \%$. Data from China Statistical Yearbook. 
Table 7. Multivariate regression analysis results 2 .

\begin{tabular}{|c|c|c|c|c|c|c|}
\hline & \multicolumn{6}{|c|}{ Tertiary industry added value growth rate } \\
\hline & (1) & (2) & (3) & (4) & (5) & $(6)$ \\
\hline \multirow{2}{*}{$\mathrm{R} 1$} & $0.656^{* * *}$ & $0.474^{* * *}$ & $-0.216^{* *}$ & $-0.191 * *$ & $-0.198^{* *}$ & -0.023 \\
\hline & $(0.029)$ & $(0.059)$ & $(0.096)$ & $(0.072)$ & $(0.072)$ & $(0.085)$ \\
\hline \multirow{2}{*}{$\mathrm{R} 2$} & & $3.361^{* * *}$ & $5.546^{* * *}$ & $3.465^{* * *}$ & $3.747^{* * *}$ & $3.912^{* * *}$ \\
\hline & & $(0.707)$ & $(0.532)$ & $(0.923)$ & $(0.707)$ & $(0.498)$ \\
\hline \multirow{2}{*}{ R3 } & & & $1.025^{* * *}$ & $0.794^{* * *}$ & $0.731^{* * *}$ & 0.207 \\
\hline & & & $(0.133)$ & $(0.107)$ & $(0.094)$ & $(0.153)$ \\
\hline \multirow{2}{*}{$\mathrm{R} 4$} & & & & $0.944^{* *}$ & $1.270^{* *}$ & -0.728 \\
\hline & & & & $(0.413)$ & $(0.454)$ & $(0.612)$ \\
\hline \multirow{2}{*}{ R5 } & & & & & $-1.000^{* *}$ & $-1.412^{* * *}$ \\
\hline & & & & & $(0.456)$ & $(0.298)$ \\
\hline \multirow[b]{2}{*}{ R6 } & & & & & & $1.739^{* * *}$ \\
\hline & & & & & & $(0.449)$ \\
\hline \multirow[t]{2}{*}{ Intercept } & $0.960^{* * *}$ & $0.714^{* * *}$ & $1.691^{* * *}$ & 0.532 & 0.295 & 0.264 \\
\hline & $(0.180)$ & $(0.086)$ & $(0.141)$ & $(0.455)$ & $(0.447)$ & $(0.390)$ \\
\hline $\mathrm{N}$ & 24 & 24 & 24 & 24 & 24 & 24 \\
\hline $\mathrm{R}^{2}$ & 0.971 & 0.903 & 0.953 & 0.991 & 0.802 & 0.996 \\
\hline
\end{tabular}

Note: ${ }^{*}$ indicates $p<0.10$, significant at $10 \%$; ${ }^{* *}$ indicates $p<0.05$, significant at $5 \%$; ${ }^{* *}$ indicates $p<0.01$, significant at $1 \%$. Data from China Statistical Yearbook.

According to the regression results in Table 7, it can be found that the multi-factor regression effect is very satisfactory. Most of the data passed the test. Among them, the disposable income growth rate of residents is not very obvious and the coefficient in the last column is negative. This means that there is multiple co-linearity between the disposable income growth rate of the residents and other factors, so we remove this factor and then perform a regression analysis of increasing factors in turn. The results are shown in Table 8.

As shown in Table 8, it can be found that the significance of each factor has improved, and it can be determined that these five factors are all influential factors in the development of China's tertiary industry. These five factors are: the level of economic development, the level of urbanization, the degree of opening up to the outside world, the level of labor in the tertiary industry, and the level of science and education.

\subsection{Province Level Data Analysis}

Based on the analysis of national-level data in Chapter 5.1, we directly used provincial-level data to examine the impact of five factors on the development of the tertiary industry in China's provinces. These five factors include: the level of economic development, the level of urbanization, the degree of openness to the outside world, the level of labor in the tertiary industry, and the level of science 
and education. We used Stata software to regress the 310 sets of province level data that have been processed. The results are shown in Table 9.

Table 8. Multivariate regression analysis results 3.

\begin{tabular}{|c|c|c|c|c|c|}
\hline & \multicolumn{5}{|c|}{ Tertiary industry added value growth rate } \\
\hline & (1) & (2) & (3) & (4) & (5) \\
\hline \multirow{2}{*}{ R1 } & $0.656^{* * *}$ & $0.474^{* * *}$ & $-0.216^{* *}$ & $-0.225^{* *}$ & $-0.060^{* *}$ \\
\hline & $(0.029)$ & $(0.059)$ & $(0.096)$ & $(0.102)$ & $(0.059)$ \\
\hline \multirow{2}{*}{ R2 } & & $3.361^{* * *}$ & $5.546^{* * *}$ & $6.107^{* * *}$ & $3.403^{* * *}$ \\
\hline & & $(0.707)$ & $(0.532)$ & $(0.860)$ & $(0.567)$ \\
\hline \multirow{2}{*}{ R3 } & & & $1.025^{* * *}$ & $1.034^{* * *}$ & $0.271^{*}$ \\
\hline & & & $(0.133)$ & $(0.141)$ & $(0.126)$ \\
\hline \multirow{2}{*}{ R5 } & & & & $-0.560^{* *}$ & $-1.402^{* * *}$ \\
\hline & & & & $(0.536)$ & $(0.292)$ \\
\hline \multirow{2}{*}{ R6 } & & & & & $1.325^{* * *}$ \\
\hline & & & & & $(0.294)$ \\
\hline \multirow[t]{2}{*}{ Intercept } & $0.960^{* * *}$ & $0.714^{* * *}$ & $1.691^{* * *}$ & $1.782^{* * *}$ & -0.025 \\
\hline & $(0.180)$ & $(0.086)$ & $(0.141)$ & $(0.180)$ & $(0.336)$ \\
\hline $\mathrm{N}$ & 24 & 24 & 24 & 24 & 24 \\
\hline $\mathrm{R}^{2}$ & 0.971 & 0.903 & 0.953 & 0.997 & 0.999 \\
\hline
\end{tabular}

Note: ${ }^{*}$ indicates $p<0.10$, significant at $10 \%$; ${ }^{* *}$ indicates $p<0.05$, significant at $5 \%$; $* *$ indicates $p<0.01$, significant at $1 \%$. Data from China Statistical Yearbook.

Table 9. Multivariate regression analysis results 4 .

\begin{tabular}{|c|c|c|c|c|c|}
\hline & \multicolumn{5}{|c|}{ Tertiary industry added value growth rate } \\
\hline & (1) & (2) & (3) & (4) & (5) \\
\hline \multirow{2}{*}{ R1 } & $0.786^{* * *}$ & $0.526^{* * *}$ & $0.412^{* *}$ & $0.308^{* *}$ & $0.215^{* *}$ \\
\hline & $(0.035)$ & $(0.051)$ & $(0.053)$ & $(0.024)$ & $(0.054)$ \\
\hline \multirow{2}{*}{$\mathrm{R} 2$} & & $3.236^{* * *}$ & $4.361^{* * *}$ & $1.375^{* *}$ & $1.344^{* *}$ \\
\hline & & $(0.794)$ & $(0.572)$ & $(1.278)$ & $(0.836)$ \\
\hline \multirow{2}{*}{$\mathrm{R} 3$} & & & $1.342^{* * *}$ & $0.843^{* * *}$ & $0.362 * * *$ \\
\hline & & & $(0.053)$ & $(0.275)$ & $(0.235)$ \\
\hline \multirow{2}{*}{ R5 } & & & & $1.735^{* *}$ & $2.235^{* *}$ \\
\hline & & & & $(0.542)$ & $(0.532)$ \\
\hline \multirow{2}{*}{ R6 } & & & & & $1.245^{* *}$ \\
\hline & & & & & $(0.743)$ \\
\hline \multirow[t]{2}{*}{ Intercept } & $0.537^{* * *}$ & $0.853^{* * *}$ & $-2.263^{* *}$ & $0.752^{* * *}$ & $0.235^{* *}$ \\
\hline & $(0.236)$ & $(0.436)$ & $(0.132)$ & $(0.523)$ & $(0.521)$ \\
\hline $\mathrm{N}$ & 310 & 310 & 310 & 310 & 310 \\
\hline $\mathrm{R}^{2}$ & 0.879 & 0.899 & 0.936 & 0.967 & 0.998 \\
\hline
\end{tabular}

Note: ${ }^{*}$ indicates $p<0.10$, significant at $10 \%$; ${ }^{* *}$ indicates $p<0.05$, significant at $5 \%$; $* *$ indicates $p<0.01$, significant at $1 \%$. Data from China Statistical Yearbook. 
As shown in Table 9, we found that the regression of provincial-level data can be found to be very different from the results of national-level data. The correlation of the regression results at the provincial level has been improved. Except that the few data items are significant at the $5 \%$ level, the other items are significant at the $1 \%$ level. It may be due to the more detailed data at the provincial level, and the factors in the regression results have never shown negative correlation. With the increase of regression factors, each item still has strong significance and maintains a positive influence on the development of the tertiary industry.

\subsection{Analysis of Empirical Results}

For the results of the above four regression analysis, the last regression analysis using provincial level data is more practical. The four regression results will be analyzed below.

For the first one-way regression, all six factors were significant at the level of $1 \%$, all of which contributed to the development of the tertiary industry. Among them, the growth rate of the proportion of employees in the tertiary industry, which represents the labor force of the tertiary industry, has the most significant impact on the growth rate of the tertiary industry's added value. For every one percentage point increase in the proportion of employees in the tertiary industry, the growth rate of the tertiary industry's value added will increase by 10.844 percentage points. For every $1 \%$ increase in the growth rate of the total value of imports and exports representing the factor of openness, the growth rate of the value added of the tertiary industry will increase by $0.656 \%$. In order to further exclude the internal correlation between the influencing factors, we performed regression analysis on all factors together.

For the second multivariate regression, it can be clearly found that the multifactor regression effect is still relatively ideal, and most of the data passed the test. However, there are two columns in which the disposable income growth rate of residents is relatively insignificant, and the coefficient is negative in the last column of regression. It shows that there is an internal correlation between the growth rate of disposable income of residents and other factors, so we consider removing this factor and then conducting a third regression analysis of sequentially increasing factors.

For the third regression analysis, it can be found that the regression results have improved, and the significance of each factor has improved. It can be judged that five factors including the level of economic development, the level of urbanization, the degree of opening up to the outside world, the level of the labor force of the tertiary industry, and the level of science and education are all factors that affect the development of the tertiary industry in China. Observing the data in the last column of Table 5, when considering the impact of these five factors on the development of the tertiary industry, the two factors of openness and the labor force of the tertiary industry have a negative correlation with the 
development of the tertiary industry. Among the remaining three positively correlated factors, the level of urbanization has the greatest effect. For every $1 \%$ increase in the proportion of urban population, the growth rate of added value of the tertiary industry will increase by $3.747 \%$. For every $1 \%$ increase in GDP per capita, the growth rate of added value of the tertiary industry will increase by $1.325 \%$. For every $1 \%$ increase in the number of graduates of ordinary colleges and universities, the growth rate of the added value of the tertiary industry increases by $0.731 \%$.

For the results of the fourth regression, it can be found that after the amount of data increases, the effect is significantly improved. Compared with the results of the third regression, there is no factor of negative correlation at all. All five factors have a positive effect on the development of the tertiary industry. This is in line with the actual situation. When a region becomes more open, it will attract more investment and tourists, which will promote the development of the tertiary industry. Improving the level of science and education can provide talent guarantee for the development of the tertiary industry, supply a large number of high-quality personnel, and better promote the development of the tertiary industry. After the level of urbanization is increased, more money is used for consumption in the tertiary industry, which can better promote the development of the tertiary industry.

\section{Conclusion}

In this paper, the growth rate of the added value of the tertiary industry is used as a measure of the development of the tertiary industry and at the same time as the explanatory variable. Based on this, we have performed a total of six regression analyses on all data. We performed two regression analyses of internal factors and three regression analyses of external factors at the national level. Finally, based on the national level data regression, a regression analysis was performed on the provincial level data.

The single factor regression analysis of the internal factors shows that the financial industry and tourism industry, which are important components of the tertiary industry, can promote the development of the entire tertiary industry. Similarly, the country's vigorous investment in education has greatly promoted the development of the tertiary industry. However, when regression analysis was performed on multiple factors, it was found that the financial industry and the education industry continued to maintain a positive correlation with the development of the tertiary industry, but the tourism industry showed a negative correlation. To investigate the reason, it should not be that the tourism industry restricts the development of the tertiary industry, but that the tourism industry has played a smaller role in promoting the development of the tertiary industry than the other two. Finance and education will radiate more industries in the tertiary industry and will play a greater role.

According to the analysis of the above empirical results, it can be determined 
that the financial industry and the education industry have an important role in promoting the development of the tertiary industry. At the same time, the level of economic development, the level of urbanization, the degree of opening up to the outside world, the labor force of the tertiary industry, and the level of science and education are factors that significantly affect the development of the tertiary industry. According to the different impact of each factor on the tertiary industry's economy, we can increase support for the financial industry, increase the intensity of elite education to provide a sufficient supply of high-quality labor for the development of the tertiary industry. We can use the tax to distribute the income twice, increase the disposable income of residents, stimulate the development of residents' tourism and service industry, so as to promote the better development of the tertiary industry. More support for the opening up of major cities to better promote the development of the tertiary industry.

In addition, there must be other factors that affect the development of the tertiary industry, but these other factors are uncertain. And it is difficult to systematically obtain data and analyze these other factors. The limitations of this paper also include the failure to systematically discuss the impact of other factors on the development of the tertiary industry, and the failure to accurately predict the future trend of the tertiary industry. At present, the indicators studied in this paper have been able to return well, and relevant conclusions have been drawn. In the future, we will conduct further research and exploration on various indicators and factors, and further discuss qualitative and quantitative analysis.

\section{Conflicts of Interest}

The author declares no conflicts of interest regarding the publication of this paper.

\section{References}

Chen, L., Huang, S., \& Li, Z. (2010). Analysis of the Impact of Financial Deepening on the Structure of the Tertiary Industry: An Analysis Based on China's Provincial Panel Data. Exploration of Economic Issues, 3, 73-79.

Clark, C. (1940). The Conditions of Economic Progress. New York: Macmillan Company.

Jiang, C. (2010). Empirical Analysis of the Factors Influencing the Development of the Tertiary Industry in Suzhou City. Economic Perspective, 22, 23-26.

Kuznets, S. (1999). Economic Growth of Various Countries. Beijing: The Commercial Press.

Li, M., \& Jiang, Z. (2010). The Principal Component Analysis on the Developmental Level of Tertiary Industry in China's Provinces. Science Technology and Industry, 10, 31-34+113.

Luo, W., Xu, F., \& He, X. (2012). Study on the Dynamic Relationship between Tourism Expansion and Economic Growth in China (1978-2008): Based on the Cointegration Test and Granger Causality Test Model. Tourism Tribune, 27, 20-26.

Su, J., Sun, G., \& Wang, L. (2011). Driving and Pulling Simulation of Tourism on the Tertiary Industry in China since 1982. Progress in Geographical, 30, 1047-1055.

Tan, Z. (2011). Research on the Internal Structural Evolution and Influence Factor of 
Tertiary Industry in Anhui Province. Master Degree Thesis, Nanjing: Nanjing University of Technology.

Xue, S. (2010). An Empirical Analysis of the Relationship between the Tertiary Industry and Economic Growth in Henan Province. Journal of Henan Business College, 23, 36-38.

Zeng, G., \& Wang, Y. (2007). Financial Development and Industrial Structure Evolution in China. Finance and Trade Economics, No. 8, 12-20.

Zhang, X., \& Zhang, S. (2014). Later Effects of the Expansion Policy of Higher Education on the Development of China's Tertiary Industry: Based on the Empirical Research of Provincial Panel Data. Science and Technology Management Research, No. 20, 160-165.

Zhao, C. (2012). Analysis on the Influencing Factors of the Development of the Tertiary Industry in Hebei Province and Countermeasures. Master Degree Thesis, Baoding: Hebei University. 